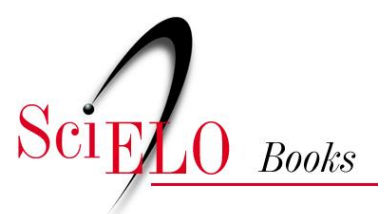

\title{
VI. Ilusões até a independência
}

\author{
Joaquim Nabuco
}

NABUCO, J. Ilusões até a independência. In: O abolicionismo [online]. Rio de Janeiro: Centro Edelstein de Pesquisas Sociais, 2011. Ilusões até a independência. pp. 30-38. ISBN: 978-85-7982070-0. https://doi.org/10.7476/9788579820700.0007.

\section{() povour}

This work is free of known copyright restrictions. http://creativecommons.org/publicdomain/mark/1.0/

Este trabalho está livre de restrições de direito de autor e/ou de direitos conexos conhecidas.

http://creativecommons.org/publicdomain/mark/1.0/

Esta obra está libre de restricciones conocidas de derechos autorales. http://creativecommons.org/publicdomain/mark/1.0/ 


\section{ILUSÕES ATÉ A INDEPENDÊNCIA}

Generosos cidadãos do Brasil, que amais a vossa pátria, sabei que sem a abolição total do infame tráfico da escravatura africana, e sem a emancipação sucessiva dos atuais cativos, nunca o Brasil firmará sua independência nacional e segurará e defenderá a sua liberal Constituição. José Bonifácio (1825)

Os abolicionistas, animando os escravos a confiarem no progresso da moralidade social, não lhes incutem uma esperança positiva, definida, a prazo certo, de cujo naufrágio possa resultar o desespero que se receia; mas quando o governo, ou quem os escravos supõem ser o governo, afiança ao mundo e ao país que emancipação é questão de forma e oportunidade, essa perspectiva de liberdade, que lhes passa diante dos olhos, tem para eles outra realidade e certeza, e nesse caso a desilusão pode ter consequências temerosas.

A animação dos abolicionistas é para o escravo como o desejo, o sonho dourado da sua pobre mãe, recordação indelével de infância dos que foram criados no cativeiro; é como as palavras que lhe murmuram ao ouvido os seus companheiros mais resignados, para dar-lhe coragem. A promessa dos poderes públicos, porém, é coisa muito diversa: entre as suas crenças está a de que palavra de rei não volta atrás, a confiança na honra dos "brancos" e na seriedade dos que tudo podem, e por isso semelhante promessa vinda de tão alto é para ele como a promessa de alforria que lhe faça o senhor e desde a qual, por mais longo que seja o prazo, ele se considera um homem livre.

O que as vítimas da escravidão ignoram é que semelhantes compromissos tomados por esses personagens são formulados de modo a nunca serem exigíveis, e que não são tomados senão porque é preciso, ao mesmo tempo, manter o escravo em cativeiro para não alienar o senhor, e representá-lo como a ponto de ficar livre para encobrir a vergonha do país. A palavra de rei podia valer no regime absoluto - não valia sempre como adiante se verá -, mas no constitucional é a máscara antiga em que os atores se substituíam no proscênio. A "honra dos brancos" é a superstição de uma raça atrasada no seu desenvolvimento mental, que adora a cor pela força que esta ostenta e lhe empresta virtudes que ela por si só não tem.

Que importa que essas promessas, letras sacadas sobre outra geração, sejam protestadas, perante o Deus em que acreditam, por tantos escravos no momento de morrer? Quem lhes ouve esse protesto? Os que ficam continuam a esperar indefinidamente, e o mundo a acreditar que a escravidão está acabando no Brasil, sem refletir que isso se dá porque os escravos estão morrendo. É difícil reproduzir todas as declarações feitas por agentes dos poderes públicos que a emancipação dos escravos no Brasil estava próxima, resolvida em princípio, só dependente para ser realizada de uma ocasião favorável. Algumas dessas declarações, entretanto, ainda estão vivas na memória de todos e bastam para documentar a queixa que fazemos.

A primeira promessa solene de que a escravidão, a qual se tornou e é ainda um estado perpétuo, seria um estado provisório, encontra-se na legislação portuguesa do século passado.

Por honra de Portugal, o mais eminente dos seus jurisconsultos não admitiu que o direito romano na sua parte mais bárbara e atrasada, dominica potestas, pudesse ser ressuscitado por um comércio torpe, como parte integrante do direito pátrio, depois de um tão grande intervalo de tempo como o que separa a escravidão antiga da escravidão dos negros. A sua frase: "servi nigri in Brasilia, et quaesitis aliis dominationibus tolerantur: sed quo jure et titulo me penitus ignorare fateor"1 é a repulsa do traficante pelo jurisconsulto e a demolição legal do edifício inteiro levantado pela pirataria dos antigos assentos. É o vexame da confissão de Melo Freire que dá um vislumbre da dignidade do alvará de 6 de junho de 1755 em que se contém a primeira das promessas solenes feitas à raça negra.

Aquele alvará, estatuindo sobre a liberdade dos índios do Brasil, fez esta exceção significativa: "Desta geral disposição excetuo somente os oriundos de pretas escravas, os quais serão conservados nos domínios dos seus atuais senhores, enquanto eu não der outra providência sobre esta matéria. A providência assim expressamente prometida nunca foi dada. Não podia, porém, deixar de repercutir no ultramar português outro alvará com força de lei relativo aos escravos de raça negra do reino. Esse

1 "Escravos negros são tolerados no Brasil e outros domínios, mas por que direito e com que título, confesso ignorá-lo completamente." 
documento é um libelo formidável e que se justifica por si só, mas também reverte com toda a força sobre o rei que denuncia por essa forma a escravidão e a tolera nos seus domínios da América e da África. ${ }^{2}$

${ }^{2}$ Estes são os termos do alvará: "Eu el-rei faço saber aos que este alvará com força de lei Estes são os termos do alvará: "Eu el-rei faço saber aos que este alvará com força de lei
virem, que depois de ter obviado pelo outro alvará de 19 de setembro de 1761 [o qual declarou livres os escravos introduzidos em Portugal depois de certa época] aos grandes inconvenientes que a estes reinos se seguiam de perpetuar neles a escravidão dos homens pretos, tive certas informações de que em todo reino do Algarve, e em algumas províncias de Portugal, existem ainda pessoas tão faltas de sentimentos de humanidade e religião, que guardando nas suas casas escravas, umas mais brancas do que eles, com nome de - pretas e negras - para, pela repreensivel propagação delas, perpetuaram os cativeiros por um abominável comércio de pecados e de usurpações das liberdades dos miseráveis nascidos daqueles sucessivos e lucrosos concubinatos; debaixo do pretexto de que os ventres das mães escravas não podem produzir filhos livres conforme o direito civil. E não permitindo nem ainda o mesmo direito civil, de que se tem feito um tão grande abuso, que aos descendentes dos escravos em que não há mais culpa que a da sua infeliz condição de cativos, se atenda à infâmia do cativeiro, além do terma que as leis determinam contra os que descendem dos mais abomináveis réus dos atrocíssimos crimes de lesa-majestade divina e humana. E considerando as grandes indecências que as ditas escravidões inferem aos meus vassalos, as confusões e os ódios que entre eles causam, e os prejuízos que resultam ao Estado de ter tantos vassalos lesos, baldados e inúteis quantos são aqueles miseráveis que a sua infeliz condição faz incapazes para os ofícios públicos, para o comércio, para a agricultura e para os tratos e contratos de todas espécies. Sou servido obviar a todos os sobreditos absurdos, ordenando como por este ordeno: Quanto ao pretérito, que todos aqueles escravos ou escravas, ou sejam nascidos dos sobreditos concubinatos, ou ainda de legítimos matrimônios, cujas mães e avós são ou houverem sido escravas, fiquem no cativeiro em que se acham durante a sua vida somente; que porém aqueles cujos cujo cativeiro vier das visavós fiquem livres e desembargados, posto que as mães e as avós hajam sido escravas; e que todos os sobreditos, por efeito desta minha paternal e pia providência libertados, fiquem hábeis para todos os ofícios, honras e dignidades sem a nota distintiva de - libertos - que a supertição dos romanos se estabeleceu nos seus costumes, e que a união cristã e a sociedade civil faz hoje intolerável no meu reino, como o tem sido em todos os outros da Europa". A data do alvará é de 16 de janeiro de 1773.

Nenhum brasileiro pode ler esse notável documento publicado há mais de um século, sobretudo as frases impressas em itálico, sem reconhecer com pesar e humilhação:

I Que a se esse alvará fosse extensivo ao Brasil a escravidão teria acabado no começo do século, antes da Independência;

II Que apesar de ser lei do século passado, e anterior à Revolução Francesa, semelhante alvará é mais generoso, compreensivo e liberal do que a nossa lei de 28 de setembro: (a) porque liberta inteiramente desde a sua data os nasciturnos, e esta os liberta depois dos vinte e um anos de idade; (b) porque declara livres e desembargados os bisnetos das escravas, e lei de 28 de setembro não levou em conta ao escravo sequer gerações do cativeiro; (c) porque isentou os escravos que declarou livres da nota distintiva de libertos - "supertição dos
Essa distinção na sorte dos escravos nas colônias e no Reino e ilhas vizinhas é a mesma que entre a sorte e a importância das colônias e a do Reino. Para o Brasil, a escravidão era ainda muito boa, para Portugal, porém, era a desonra. A área desse imenso Império posta em relação com o pudor e a vergonha nacional era muito limitada, de fato não se estendia além do Reino e não o abrangia todo. Mas apesar disso o efeito daquela impugnação enérgica à imoralidade e aos abusos da escravidão não podia ser recebido pelos senhores e pelos escravos no Brasil senão como o prenúncio da mesma providência para o ultramar.

Depois veio o período da agitação pela Independência. Nessa fermentação geral dos espíritos, os escravos enxergavam uma perspectiva mais favorável de liberdade. Todos eles desejavam instintivamente a Independência. A sua própria cor os fazia aderir com todas as forças ao Brasil como pátria. Havia nele para a raça negra um futuro; nenhum em Portugal. A sociedade colonial era por sua natureza uma casa aberta para

romanos que a união cristã e a sociedade civil" fazia já nesse tempo ("faz hoje") "intolerável no reino", ao passo que a nossa lei de 1871 não se lembrou de apagar tal nódoa, e sujeitou os libertos de qualquer de seus parágrafos por cinco anos à inspeção do governo e à obrigação de exibir contrato de serviço sob pena de trabalhar nos estabelecimentos públicos. O visconde do Rio Branco disse mesmo no Conselho de Estado, antes de ler esse alvará, cujas palavras qualificou de memoráveis, que a lei portuguesa "estendeu esse favor (o de declará-los livres e ingênuos) aos infantes que fossem libertados no ato de batismo, e aos libertos que se achassem em certas classes", e acrescentou - "o que não se poderia fazer entre nós sem ferir a Constituição do Império". A ser assim, isso mostra somente a diferença entre a compreensão das exigências da união cristã (a Constituição foi feita em nome da Santíssima Trindade) e da sociedade civil que tinha o imperador constitucional em 1824 e a que tinha o rei absoluto em 1773 .

III Que hoje apesar de ser a escravidão do Brasil resultado exclusivo, além do tráfico, das mesmas causas apontadas no alvará, "das usurpações das liberdades de miseráveis nascidos de sucessivos e lucrosos concubinatos", da repreensível propagação das escravas, de pretextos tirados do direito civil, "de que se tem feito um tão grande abuso"; e apesar de ser infinitamente maior o número de vassalos (os escravos nem mesmo são hoje assim chamados, isto os faria subir na escala social) ou, seguindo a evolução daquela palavra, de súditos do chefe de Estado "lesos, baldados e inúteis", tornados pela "sua infeliz condição incapazes para os tratos e contratos de todas as espécies"; ainda assim essas duras verdades nãosão mais ditas à escravidão do alto do trono. "A infâmia do cativeiro" continua a recair não sobre o que inflige, podendo não o infligir, mas sobre o que o sofre, sem poder evitá-lo. Esse alvará antiquado e que deverá ser obsoleto parece representar um período da moralidade pública, religiosa, social e política, muito mais adiantado do que o período, que é o atual, representado pela matrícula geral dos escravos. 
todos os lados onde tudo era entrada; a sociedade da mãe pátria era aristocrática, exclusiva, e de todo fechada à cor preta. Daí a conspiração perpétua dos descendentes de escravos pela formação de uma pátria que fosse também sua. Esse elemento poderoso de desagregação foi o fator anônimo da Independência. As relações ente os cativos, ou libertos, e os homens de cor, entre estes e os representantes conhecidos do movimento, formam a cadeia de esperanças e simpatias pela qual o pensamento político dos últimos infiltrou-se até as camadas sociais constituídas primeiros. Aliados de coração dos brasileiros, os escravos esperaram e saudaram a Independência como o primeiro passo para a sua alforria, como uma promessa tácita de liberdade que não tardaria a ser cumprida.

Uma prova que no espírito não só desses infelizes como também no dos senhores, no dos inimigos da Independência, a ideia estava associada com a de emancipação, é o documento dirigido ao povo de Pernambuco, depois da Revolução e 1817, pelo governo provisório. Esta proclamação, notável por mais de um título, não é tão conhecida quanto o patriotismo brasileiro tem interesse em que o seja, e por isso a transcrevo em seguida. Ela é hoje um monumento político elevado em 1817 a uma província que representa na história do Brasil o primeiro papel, pela sua iniciativa, seu heroísmo, seu amor à liberdade e seu espírito cavalheiroso, mas em cuja face a escravidão imprimiu a mesma nódoa que em todas as outras:

Patriotas pernambucanos! A suspeita tem se insinuado nos proprietários rurais: eles creem que a benéfica tendência da presente liberal revolução tem por fim a emancipação indistinta dos homens de cor e escravos. O governo lhes perdoa uma suspeita que o honra. Nutrido em sentimentos generosos não pode jamais acreditar que os homens, por mais ou menos tostados degenerassem do original tipo de igualdade; mas está igualmente convencido de que a base de toda sociedade regular é a inviolabilidade de qualquer espécie de propriedade. Impelido destas duas forças opostas, deseja uma emancipação que não permita mais lavrar entre eles o cancro da escravidão; mas a deseja lenta, regular e legal. O governo não engana ninguém; o coração se lhe sangra ao ver tão longínqua uma época tão interessante, mas não a quer prepóstera. Patriotas: vossas propriedades, ainda as mais opugnantes ao ideal da justiça serão sagradas; o governo porá meios de diminuir o mal, não o fará cessar pela força. Crede na palavra do governo, ela é inviolável, ela é santa.
Essas palavras são as mais nobres que até hoje foram ditas por um governo brasileiro em todo o decurso da nossa história. Nem a transação que nelas parece haver com o direito de propriedade do senhor sobre o escravo desfigura-lhe a nobreza. Está-se vendo que essa "propriedade" não tem legitimidade alguma perante os autores da proclamação, que esse fato os envergonha e humilha. Os revolucionários de Pernambuco compreenderam e sentiram a incoerência de um movimento nacional republicano que se estreava reconhecendo a propriedade do homem sobre o homem, e não há dúvida que essa contradição deslustrou para eles a independência que proclamaram. Essa revolução que no dizer dos seus adeptos "mais pareceu festejo de paz que tumulto de guerra", essa alvorada do patriotismo brasileiro que tem a data de 6 de março de 1817, foi o único de todos os nossos movimentos nacionais em que os homens que representavam o país coraram de pejo, ou melhor, choraram de dor, ao ver que a escravidão dividia a nação em duas castas, das quais uma, apesar de partilhar a alegria e o entusiasmo de outra, não teria a mínima parte nos despojos da vitória. Que significa, porém, aquele documento em que a necessidade de aliciar proprietários rurais não impediu o governo de dizer que desejava a emancipação, lenta, regular e legal, que o coração se lhes sangrava, que a propriedade escrava era a mais opugnante ao ideal de justiça e que ele poria meios de diminuir o mal? Significa que os mártires da Independência se viram colocados entre a escravidão e o cadafalso; temendo que a união dos "proprietários rurais" com as forças portuguesas afogasse em sangue esse primeiro sonho realizado de um Brasil independente, se o fim da colônia se lhes afigurasse como o fim da escravidão.

Isso dava-se no Norte. Que no Sul a causa da Independência esteve intimamente associada com a da emancipação, prova-a a atitude da Constituinte e de José Bonifácio. Aquela em um dos artigos do seu projeto de Constituição inscreveu o dever da assembleia de criar estabelecimentos para a "emancipação lenta dos negros e sua educação religiosa e industrial". A Constituição do Império não contém semelhante artigo. Os autores desta última entenderam não dever nodoar o foral da emancipação política do país, aludindo à existência da escravidão, no presente. A palavra libertos do artigo pelo qual esses são declarados cidadãos brasileiros e do artigo 94, felizmente revogado, que os declarava inelegíveis para deputados, podia referir-se a uma ordem anterior à Constituição e destruída por esta. No mais os estatutos da nossa nacionalidade não fazem referência à escravidão. Essa 
única pedra, posta em qualquer dos recantos daquele edifício, teria a virtude de convertê-lo com sua fachada monumental do artigo 179 num todo monstruoso. Por isso os organizadores da Constituição não quiseram deturpar a sua obra descobrindo-lhes os alicerces. José Bonifácio, porém, o chefe desses Andradas - Antônio Carlos tinha estado muito perto do cadafalso no movimento de Pernambuco - em quem os homens de cor, os libertos, os escravos mesmos, todos os humildes da população que sonhavam a Independência tinham posto a sua confiança, redigira para ser votado pela Constituinte um projeto de lei sobre os escravos.

Esse projeto para o abolicionismo atual é insuficiente, apesar de que muitas das suas providências seriam ainda hoje um progresso humanitário em nossa lei; mas se houvesse sido adotado naquela época, e sobretudo se o "patriarca da Independência" houvesse podido insuflar nos nossos estadistas desde então o espírito largo e generoso de liberdade e justiça que o animava, a escravidão teria por certo desaparecido do Brasil há mais de meio século.

Artigos como estes, por exemplo - os quais seriam repelidos pela atual legislatura com indignação -, expressam sentimentos que, se houvesse impulsado e dirigido séria e continuamente os poderes públicos, teriam feito mais do que nenhuma lei para moralizar a sociedade brasileira.

Artigo 5. Todo escravo, ou alguém por ele, que oferecer ao senhor o valor por que foi vendido, ou por que for avaliado, será imediatamente forro. - Artigo 6. Mas se o escravo ou alguém por ele, não puder pagar todo o peço por inteiro, logo que apresentar a sexta parte dele, será o senhor obrigado a recebê-la, e lhe dará um dia livre na semana, e assim à proporção mais dias quando for recebendo as outras sextas partes até o valor total. - Artigo 10. Todos os homens de cor forros, que não tiverem ofício ou modo certo de vida, receberão do Estado uma pequena sesmaria de terra para cultivarem, e receberão, outrossim, dele os socorros necessários para se estabelecerem, cujo valor irão pagando com o andar do tempo. Artigo 16. Antes da idade de doze anos não deverão os escravos ser empregados em trabalhos insalubres e demasiados; e o Conselho [o Conselho Superior Conservador dos Escravos, proposto no mesmo projeto] vigiará sobre a execução deste artigo para o bem do Estado e dos mesmos senhores. - Artigo 17. Igualmente os conselhos conservadores determinarão em cada província, segundo a natureza dos trabalhos, as horas de trabalho, e o sustento e o vestuário dos escravos. - Artigo 31. Para vigiar na estrita execução da lei e para se promover por todos os modos possíveis o bom tratamento, morigeração e emancipação sucessiva dos escravos, haverá na capital de cada província um Conselho Superior Conservador dos Escravos.

E assim diversos outros artigos sobre penas corporais, serviços das escravas no tempo, e logo depois da gravidez, casamentos e instrução moral dos escravos, mercês públicas aos senhores que dessem alforria a famílias, posse de escravos por eclesiásticos.

Não há na lei de 28 de setembro nada nesse sentido que revele cuidados e desvelos pela natureza humana no escravo: o legislador neste caso cumpriu apenas um dever, sem amor, quase sem simpatia; naquele, em falta da liberdade imediata que lhe pesava não poder decretar, ele mostrou pelas vítimas da injustiça social o mais entranhado interesse, carinho mesmo, que não podia deixar de ir-lhes direto ao coração.

É entretanto no magnífico, e - lido hoje à luz da experiência dos últimos sessenta anos - melancólico apelo dirigido aos brasileiros por José Bonifácio do seu exílio na França ${ }^{3}$ que se pode achar a concepção do estadista de que o Brasil com a escravidão não era uma pátria digna de homens livres:

Sem a emancipação dos atuais cativos nunca o Brasil firmará sua independência nacional e segurará e defenderá a sua liberal constituição. Sem liberdade individual não pode haver civilização, nem sólida riqueza; não pode haver moralidade e justiça, e sem estas filhas do céu, não há nem pode haver brio, força e poder entre as nações.

\footnotetext{
${ }^{3}$ Até que ponto as ideias conhecidas de José Bonifácio sobre a escravidão concorreram para fechar ao estadista que planejou e realizou a Independência a carreira política em seu próprio país, é um ponto que merece ser estudado. Talvez quem empreender esse estudo, venha a descobrir que a escravidão não teve pequena parte nesse ostracismo, como também provavelmente foi ela que entregou os nacionalistas pernambucanos ao cadafalso. Em todo o caso nas seguintes palavras escritas por Antônio Carlos ver-se-á mais um efeito político do regime que, assentando sobre ela, só pode ser o do servilismo e da ingratidão. "Tal foi José Bonifácio, viveu e morreu pobre; não recebeu da sua Nação distinção alguma; no Senado que a lei criara para o mérito e a virtude, e onde tem achado assento até o vício, a crápula, a inépcia, a intriga e a traição (não esquecendo o tráfico) não houve nunca um lugar para o criador do Império". "Talvez por isso", acrescenta Antônio Carlos, "mais sobressairá seu nome, como os de Bruto e Cássio mais lembrado eram por não aparecerem suas estátuas nas pombas fúnebres das famílias a que pertenciam". Esboço biográfico e necrológico do conselheiro José Bonifácio de Andrada e Silva, p. 16.
} 
Essa defesa ardente, essa promoção espontânea e apaixonada dos direitos dos escravos pelo mais ilustre de todos os brasileiros, teve origem nos extremos do seu patriotismo, no desejo de completar a sua grande obra, porém não foi de certo estranha a convicção de que a Independência, com o cativeiro indefinido, isto é, perpétuo, dos escravos, era um golpe cruel na esperança de que estavam possuídos todos eles, nos anos que precederam e nos que seguiram aquele acontecimento, instintivamente, só por serem testemunhas do entusiasmo da época, e por terem respirado o mesmo ar que dilatava todos os corações. A independência não foi uma promessa formal, escrita, obrigatória, feita pelos brasileiros aos escravos; não podia porém deixar de ser, e foi, e assim o entenderam os mártires pernambucanos e os Andradas, uma promessa resultante da afinidade nacional, da cumplicidade revolucionária, e da aliança tácita que reunia em torno da mesma bandeira todos os que sonhavam e queriam o Brasil independente por pátria. 